\title{
The Study on Optimized Program of Landscape Engineering Based on BIM Technology
}

\author{
Jinfu Zuo \\ \{ zuojinfu08@163.com\} \\ Hainan College of Vocation and Technique Haikou, 570216/Hainan, China
}

\begin{abstract}
With the rapid development of China's urbanization process, the rapid growth of investment in fixed assets, which led to the leap forward development of the construction industry. High-rise, long-span structures are emerging, architectural structure and architectural form more and more complex, a variety of complex curved surface is more and more used in the construction, at this time, to 2D landscape engineering construction plans due to the visualization is not strong, understanding of drawings increased a lot of difficulty, among architecture, structure, equipment, professional designers, communication between designers and constructors will produce some obstacles. At the same time, because of the complexity of the landscape engineering and construction process of these buildings, traditional landscape engineering construction method and model has been unable to meet the requirements and need to use computer technology, network technology, virtual reality technology, multimedia technology, H dimension digital technology, Gou Jianguan wear period decision-making, implementation period and operation period of the computer management system, realize the design and landscape engineering construction scheme optimization, garden construction process dynamic simulation and virtual landscape engineering construction, construction the whole process of information sharing.
\end{abstract}

Keywords: BIM technology; construction scheme optimization; grey system; PERT model; virtual construction

\section{Introduction}

Landscape engineering industry of speeding the development of the technology and management level proposed higher requirements, needs a corresponding construction mode, give full play to the design under the jurisdiction of shooting action, from the point of view of the whole life cycle, the preliminary planning, design, construction, operation and integration. With the continuous emergence of high-rise, long-span structure, landscape structure and landscape engineering modeling is becoming more and more complex, a variety of complex surface in the garden engineering application is more and more, like Shanghai, CCTV, the building and the upcoming construction of long: sand the skies of the city more and more complex landscape engineering and super high-rise garden project continue to appear around us. At this time [1], w 2D drawings because of the visualization is not strong, understanding of drawings increased a lot of difficulty, landscape engineering, structure, equipment, professional designers, communication between designers and constructors will produce some obstacles. And because of these landscape engineering construction is a complex process, 
traditional construction methods and models have been unable to meet the requirements, need to use the computer technology, network technology, virtual reality technology, multimedia technology, $\mathrm{H}$ dimension digital technology, construction throughout the decision-making stage, the implementation stage and during the operation of the computer management system, realize the design and construction scheme optimization, construction process dynamic simulation and virtual construction, construction the whole process of information sharing. At present, the application of computer in landscape engineering design is mainly CAD drawing technology. CAD technology compared with the drawing board and hand tools such as pencil drawing can greatly improve the drawing efficiency. However, due to the use of twodimensional plane, elevation, section performance, and people in the real life of the dimension of $\mathrm{H}$ dimension to think about the problem, in reading the two-dimensional drawings of the need to have a certain professional knowledge.

\section{BIM Technology and Virtual Construction}

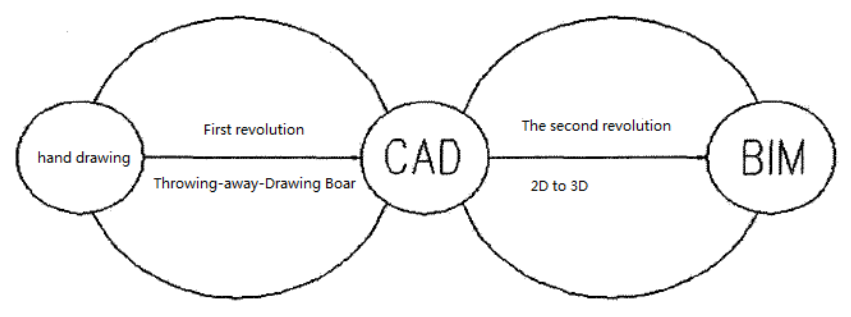

Fig. 1. The two revolution of landscape engineering

In comparison, the definition of American national standard of BIM relatively complete: $\mathrm{BM}$ uses digital representation to express the physical and functional characteristics of a building project; BIM provides a sharing of knowledge resources, is a share of the facilities information, for the facilities from concept to all the demolition decision in the life cycle and provide a reliable basis; in the different stages of development, different stakeholders in the BIM through extraction, insert, update and modify information, collaborative $\mathrm{W}$ support and reflect their respective responsibilities generally believe that the construction industry for a total of two revolutionary changes: the first revolution, the use of CAD technology the construction industry has entered the computer era; BIM technology ushered in the construction industry of the second revolution, led the entire construction industry into a letter the age of information [2].

\subsection{BIM Support Project Life Cycle}

In the use of BIM technology to design, the first use of BIM technology to determine the architectural program, building 3D building plans, as shown in figure 2. Based, adding time coordinate form 4D expression and mold clever construction, will be the progress of the project the image displayed, forming dynamic construction process simulation, found in advance at the top of a series of problems existing in the project construction, advance modified and prevention; establish a relationship between the model and the cost of the 
formation of 5DBIM, 5DBIM technology compared with the traditional technology has great advantages, to avoid in the process of the construction project of coarse estimation of, can obtain the accurate cost results in a very short time, and be able to design any changes to re estimate the. Construction side to better management of materials, machinery, and other import and field, and this efficiency compared to the cost of traditional process is unimaginable, and through the $5 \mathrm{D}$, each part of the expenditure more transparent are also more likely to see a project which block is the need to focus on [3].

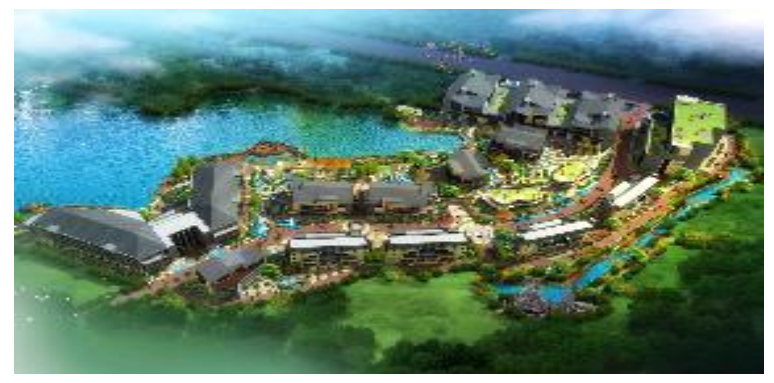

Fig. 2. BIM design case presentation

\subsection{BIM Support Project Life Cycle}

Visual function as a major highlight of the BIM technology, it not only replaces the original two-dimensional and not intuitive CAD technology, but also can be carried out to deepen the design and 4D visual simulation. For each stage of construction process and related information are not very good communication problems resolved, to ensure the orderly conduct of construction, the implementation of real-time monitoring of the construction quality and progress, try to avoid a series of problems such as rework, make project time, cost and quality to reach the expected standards; the owner has saved the calculation of engineering quantity time, using BIM visualization of this technology can directly know the W demand for cement, steel and other engineering, let BIM become a highlight in the bidding; designskillful through the discovery of BIM visualization technology can directly view the problems existing in the design and project design with an overall grasp.

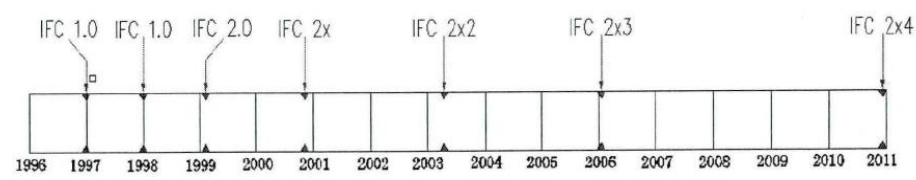

Fig. 3. IFC standard development history

\subsection{Virtual Construction Technology}

With the accelerated process of urbanization in China, the total output value of the construction industry has maintained a trend of accelerated growth. But the pressure is the level of productivity of construction industry decreased year by year, far behind the manufacturing industry. Building materials, human, and material costs rise which is part of the reason, another reason is because of the construction project is becoming more and more complex, design, construction, rework times more and more high, this part against accounted 
for about $12 \%$ of the whole construction cost to $22 \%$. Low productivity is a waste of resources for China, a country with huge construction market. Referring to the manufacturing management experience, the virtual construction technology is introduced into the construction industry to carry out the production and production efficiency. Roaming system as the foreign virtual construction system is the main research object, the main performance in the field of Architecture: 1. The shape and design plan. The construction process of planning and management; 3 . The programme of construction budget. Virtual construction can also be $\mathrm{w}$ is used to optimize the design, the designer through parametric modeling 3D information model, the model contains the building structure Noyes and pipe network, etc.. Through this information model, the platform can be designed to detect and modify the $\mathrm{W}$, so as to find the design conflict and the construction of the problem. After the discovery of the problem through the virtual platform and an information model for the timely and effective communication so as to solve the problem, through a design for detection and communication design of repeated cycle process, pre construction to solve all problems of the design of the, the feasibility of the construction of the laid a solid foundation [4].

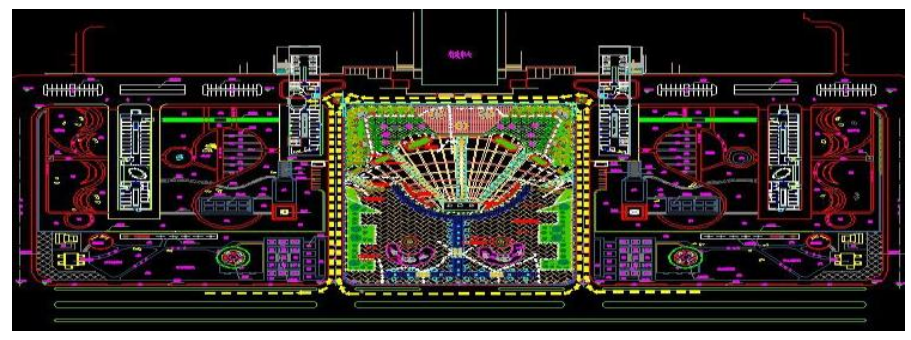

Fig. 4. Virtual construction CAD diagram

\section{Application of BIM Technology in Design and Construction}

The beginning of a BIM Technology is a kind of design idea and the working pattern, so for the construction and design of Bim in the field of tension promotion must first in the design industry, and then through the design of driven construction. Currently domestic BIM application in Design Institute is still relatively early but also in the primary stage, a variety of large-scale design institute such as CMC international has carried out the study of BIM software. Through the study of change the original 2-D design thinking to allow the designer to slowly come to accept the three dimensional design, in order to achieve the transformation of design thinking. Construction organization design mainly by the establishment basis and the principle, the scope of preparation, engineering survey, engineering, general arrangement and arrangement of construction schedule, construction technical scheme, time limit for a project assurance measures, quality objectives and ensure $\mathrm{w}$ system and guarantee measures, emergency rescue plan, environmental protection measures, seasonal construction assurance measures, civilized construction requirements. Construction organization design is the construction project overall document. For construction Ju fabric design nuclear Tun, the construction scheme is reasonable will and the level of project cost, time limit for a project and $\mathrm{W}$ construction quality has a close relationship. For the construction side, a good 
construction scheme can ensure the successful bid of the project and the construction of an orderly. The contents of the construction scheme, including the construction sequence, construction machinery selection, construction methods, construction methods, the principle of selection of $\mathrm{W}$ and evaluation of the construction scheme of the indicators, etc. Construction quality and safety indicators for construction projects is particularly important. It is not only related to the use of the project and key index investment tension investment return rate is the people's life and property safety can be guaranteed. Effective control of quality and safety is an important factor to ensure the quality and quantity of the project. The quality and safety of the second indicators include: the quality assurance level, the degree of safety and civilized construction [5].

Make detailed construction process for concrete construction plan to some key points and difficulties of the $\mathrm{W}$ and practice arrangement, circuitous mining tension what method can prevent the emergence of quality and safety risks, take what method can $\mathrm{w}$ to ensure the construction quality and improve the operation reliability, which is handicraft operation measures. Construction technology is the foundation of guiding the construction, it is also the key factor to ensure the economic indicators, quality and safety indicators, the time limit for the project to reach the standard. Its second level refers to the bridge contains: construction process index and construction mechanization degree index. The basic idea of the grey relational analysis is to judge whether the relationship is close, the curve is close to the similarity degree of the geometric shape of the sequence curve, the relationship between the curve and the corresponding sequence is bigger, and vice versa. The purpose of grey relational analysis is to analyze the system of the information is not complete with the "few data uncertainty". Grey relational decision-making is one of the functions of grey relational analysis. The technical connotation of grey relational analysis can be concluded as $\mathrm{W}$, and then the order relation of the gray correlation degree is established. W can also be used in the optimization of the grey relational decision theory in the construction program, through the establishment of the difference between the space of the space between the gray correlation degree, through the sequence of the construction scheme to obtain the optimal construction scheme.

\section{Conclusion}

The virtual construction based on BIM technology is studied, and the main software is analyzed, and the content and the implementation procedure of virtual construction are studied. The application of the BIM Technology at home and abroad, research skillfully shows that: the government, the owners push BIM Technology Development of nuclear power. Find out the opportunities and challenges brought by the BIM technology to the project, and put forward the BIM technology based on the combination of research and development of cloud technology is the only way. Through the analysis of the construction scheme, the evaluation of the construction scheme of the 12 indicators, the use of expert scoring method to quantify the indicators, according to the importance of the index attached to the corresponding weight value. The grey system theory is introduced to deal with the quantitative indicators, the grey decision model and grey relational model are established, and the optimal construction scheme is obtained by comparing the accuracy of the test scheme. This paper presents an improved PERT model based on grey system, the planning period into pressure optimization. 


\section{Acknowledgements}

Natural science foundation of Hainan provi. In 2014 (314093). Project on educational teaching reform of Hainan provi. In 2016. (Hnjg2016-63).

\section{References}

[1] Wang Zhixian. Construction scheme and project cost control. Henan science and Technology. No. 05. (2011)

[2] Pay Shengliang. Construction scheme analysis of. Impact on economic construction bidding price control. No. 01. (2015)

[3] Jianlin. Analysis of the effect of construction scheme in construction project management of the. (On a modern property). No. 05. (2015)

[4] Zhou Ding. Analysis of the impact of highway engineering construction project on the engineering cost. Value engineering. No. 33. (2012)

[5] Gao Xiaochu. An entropy based construction scheme for determining. Cooperative economy and technology. No. 14. (2012) 